\title{
ACUTE PAINT THINNER TREATMENT INDUCES CELL DEATH IN CULTURED NEURONS AND ASTROCYTES
}

\author{
Hanaa Malloul $^{1}$, Mohammed Bennis ${ }^{2}$, Soraya L. Valles ${ }^{3}$, Francisco E. Olucha-Bordonau ${ }^{4}$, \\ Saadia Ba-M'hamed ${ }^{5}$ \\ ${ }^{1,2,5}$ Laboratory of Pharmacology, Neurobiology and Behavior (URAC-37), Faculty of Sciences Semlalia, University \\ Cadi Ayyad, Marrakech, Morocco \\ ${ }^{3}$ Department of Physiology, Faculty of Medicine, University of Valencia, Blasco Ibañez 15, 46010, Valencia, Spain \\ ${ }^{4}$ Department of Medicine, Faculty of Health Sciences, University Jaume I, Campus del Riu Sec s/n, Castellón, Spain
}

\begin{abstract}
Background: Paint thinner is a highly toxic chemical solvent, that when inhaled has many psychoactive properties. Chronic abuse of inhalants in humans leads to pronounced neurobiological and neuropsychological impairments; however, limited studies have demonstrated the cytotoxic effects of exposure to organic solvents in its complex mixture form.

Objectives: Neuronal cells could be affected by exposure to thinner as it contains a vast mixture of volatile solvents that synergistically could have a direct effect on biology and viability of these cells. The present study aimed to test the toxicity of thinner on metabolic activities of neurons and astrocytes in primary cell culture.

Methods: For the assessment of acute effects of thinner treatment on neuronal cells and the evaluation of the dose-and timeresponse dependencies, cultured neurons and astrocytes were treated acutely by gradually increased concentrations of thinner during different time of incubation. The MTT assay was used to estimate the cytotoxicity of the solvent.

Results: Our results demonstrate that the thinner has an important cytotoxic effect and induces concentration-dependent cell death in both cultured neurons and astrocytes. In addition, the fact that the viability of glial cells is the only dependent on the exposure time demonstrated that the toxic effect causes a stronger degeneration over neurons than glial cells.

Conclusions: The thinner has a cytotoxic effect on neurons and glial cells. We suggest that the wide range of neurological symptoms produced by inhalant exposure can be correlated with the direct effect of the solvent on the biology of neuronal cells.
\end{abstract}

Keywords: Paint Thinner, Neurons, Astrocytes, Cell Culture, MTT, Cell Death.

\section{INTRODUCTION}

Paint thinners are chemical mixtures of organic solvents frequently utilized to dilute oil-based paints and as industrial cleaning agents [1,2]. In addition, because of their highly rewarding acute effect, they have been used as a drug of abuse by adolescents of low-income social class throughout the world $[3,4,5,6]$.

Data on human consistently demonstrate that chronic exposure to inhalants is related to relevant toxic effects, including neuropsychological impairment, diffuse and subtle changes in white matter [7,8]. Though, a plethora of preclinical research has tended to focus on acute exposure without any assessment of the toxicological mechanisms underlying these effects [9]. In our laboratory, we have already assessed the effects of acute and chronic exposure to different concentrations of paint thinner on multiple behavioral functions in mice including anxiety, locomotors activity and working and long-term spatial memory [10]. We have demonstrated also that the acute behavioral effects of thinner inhalation were correlated with neuronal activation in multiple brain structures. Toluene, one of principal solvent components of paint thinner used [10,11], decreases neuronal activity in vitro and causes mental depression, loss of memory and cognitive impairments in vivo $[12,13]$. In humans, toluene inhalation produces mental confusion such as euphoria, hallucination and delusion, and disturbance in motor coordination [14,15]. In animals, toluene induces biphasic effect on locomotor activity, from motor excitation at low concentrations to sedation, motor impairment and anesthesia at higher concentrations $[16,17,18,19,20]$. In addition, animals exposed to low levels of toluene exhibit anticonvulsant [21,22,23] and anxiolyticlike effects $[24,25,26]$. Beside the effect on myelin metabolism, the components of the paint thinner could have a direct effect on neural cells affecting their viability. Conversely, toxicology mechanism of thinner exposure as mix is not frequently studied. However, to our knowledge, the effect of thinner on the neurons and astrocytes viability has not been studied before. In this study, therefore, we aimed to determine the degree of the toxicity of different thinner doses on neurons and astrocytes in vitro at several exposure times.

\section{MATERIAL AND METHODS}

\subsection{Animals}

Cortical neuronal and glial cells used in our culture study were obtained from E-14 and E-21 rat embryos from facilities care of the University of Valencia. All 
experimental procedures were performed to minimize animal suffering and to reduce the number of animals used. Protocols used were approved by the Ethics Committee for Animal Research of the University of Valencia based on the local guidelines Spanish law 32/2007.

\subsection{Primary Culture of Cortical Astrocytes}

They were prepared from the cerebral cortex of 21-day-old rat fetuses, as previously described [27]. Briefly, under toxin-free sterile conditions, the cerebral cortex was dissected and dissociated mechanically by pipetting 10 times with Dulbecco's modified Eagle's medium (DMEM, Gibco Invitrogen Corporation, Barcelona, Spain) (10 $\mathrm{ml}$ for the cortex obtained from 12-14 fetuses). Cell suspension was filtered through a nylon mesh with a pore size of $90 \mu \mathrm{m}$ and plated $\left(5 \times 10^{4}\right.$ cells $\left./ \mathrm{cm}^{2}\right)$ in DMEM containing $20 \%$ fetal bovine serum (FBS) (Gibco Invitrogen Corporation, Barcelona, Spain), supplemented with L-glutamine (1\%), HEPES (10 $\mathrm{mM})$, fungizone $(1 \%)$ and antibiotics $(1 \%)$. Cultures were grown in a humidified atmosphere of $5 \%$ $\mathrm{CO} 2 / 95 \%$ air at $37^{\circ} \mathrm{C}$. After 1 week of culture, the FBS content was reduced to $10 \%$ and the medium was changed twice a week.

\subsection{Primary Culture of Cortical Neurons}

Cerebral cortexes were dissected from 14- or 15-day-old rat fetuses under sterile conditions [28]. Briefly, the isolated brain tissues were digested mechanically by pipetting 10 times with $10 \mathrm{ml}$ pipette in Neurobasal medium (Gibco Invitrogen Corporation, Barcelona, Spain). Dissociated cells were filtered (through a nylon mesh with a pore size of 90 $\mu \mathrm{m})$ and plated $\left(5 \times 10^{4} \mathrm{cells} / \mathrm{cm}^{2}\right)$ on poly-L-lysine-coated dishes. After attachment of the cells (1h), the plating medium was changed to Neurobasal containing $10 \%$ FBS supplemented with antibiotics (1\%) and fungizone (1\%). Cultures were grown in a humidified atmosphere of $5 \%$ $\mathrm{CO} 2 / 95 \%$ air at $37^{\circ} \mathrm{C}$ for 3 days. Cells were then exposed to cytosine- $\beta$-D-arabino-furanoside $(5 \mu \mathrm{M})$ for $24 \mathrm{~h}$ to inhibit proliferation of non-neuronal cells. The purity of cultures of astrocytes and neurons obtained by these methods has been previously shown $[27,28]$.

\subsection{Cell Treatment}

10 days after primary culture of neurons and astrocytes, the paint thinner was added to the suspension medium in the corresponding plates $(n=3)$. Gas chromatography and single wavelength monitoring spectrometry (Chemistry Analysis and Characterization Centre, University Cadi Ayyad, Marrakech) was used to determine the relative concentration of each chemical component of the solvent. The paint thinner solution was comprised of Toluene (24.46\%), Xylène (15.47\%), Benzene (10.67\%), Dichloromethylene $(6.34 \%)$ and Acetone $(5.55 \%)$. The remaining components were the minority with less than $2 \%$ each [10].

Thinner was previously dissolved in culture medium with fetal bovine serum $(10 \%)$. We added the corresponding amount of thinner to plates containing 499, 498, and $496 \mu \mathrm{l}$ of culture medium in order to get either $0.2 \%, 0.4 \%$ or $0.8 \%$ of thinner in the culture medium (either $1 \mu \mathrm{l}, 2 \mu \mathrm{l}$ and $4 \mu \mathrm{l}$ respectively). To evaluate the effect of the solvent in the course time, the cells were incubated during different time (1h, 6h and 24h).

\subsection{Determination of Cell Viability}

Cell viability was measured using the 3-(4,5-Dimethyl-2thiazolyl)-2,5-diphenyl-2H-tetrazolium (MTT) reduction assay. MTT bromide reduction assay was used to determine the cellular-reducing capacity through the extent of MTT reduction to the insoluble intracellular formazan [29], which depends on the activity of intracellular dehydrogenases, but not on the integrity of the plasma membrane. After treatments, medium was removed and the cortical neurons and astrocytes were incubated with MTT $(0.5 \mathrm{mg} / \mathrm{ml}$ in PBS) for $4 \mathrm{~h}$ at $37^{\circ} \mathrm{C}$. The medium was aspirated and the formazan particle was dissolved in dimethyl sulphoxide. The relative amount of MTT reduction was determined based on the absorbance measured at $595 \mathrm{~nm}$. The cell viability was normalized relative to control cells whose viability was taken as $100 \%$ and expressed as a percentage in each condition. Cell viability in controls, as measured by the release of lactate dehydrogenase activity to the extracellular medium, was always $>90 \%$.

\subsection{Statical Analysis}

Results were reported as mean \pm SEM. Data were analyzed by using one-way analysis of variance (ANOVA) (to evaluate the difference between treated groups and control group after each time of incubation) and two-way ANOVA (to analyze the effects of incubation time and dose of thinner on cell viability) followed by Bonferroni post hoc test. The results were analyzed by using the program GraphPad Prism and the differences were considered significant at $\mathrm{p}<0.05$.

\section{RESULTS}

\subsection{Pre-incubation with the Thinner Induces}

\section{Neuronal Cell Death}

In cultured neurons, acute incubation with different doses of paint thinner showed a highly significant reduction of neuronal viability after 1 hour compared to control groups $\left(\mathrm{F}_{(3,8)}=15.11, \mathrm{P}<0.01\right)$ (Fig. 1.A). The number of viable neurons was reduced with $0.2,0.4$ and $0.8 \%$ of thinner respectively to $31.41 \pm 10.81 \%, 30.73 \pm 24.79 \%$ and to $29.05 \pm 15.21$. However, the comparative analysis between treated groups remained non-significant $\left(\mathrm{F}_{(2,6)}=0.01, \mathrm{P}=\right.$ $0.98)$.

After 6 hours of incubation with thinner, a graded percentage of viability was observed at increased concentrations. Indeed, only $28.78 \pm 17.56 \%, 26.96 \pm 2.05 \%$ and $14.17 \pm 2.56 \%$ of viable neurons were found when incubated respectively with $0.2 \%, 0.4 \%$ and $0.8 \%$ of thinner (Fig. 1B). Thus, we found a significant difference between the treated groups and the control group $\left(\mathrm{F}_{(3,8)}=56.90, \mathrm{P}<\right.$ $0.001)$, but no significant difference between the treated groups $\left(\mathrm{F}_{(2,6)}=1.78, \mathrm{P}=0.24\right)$. 

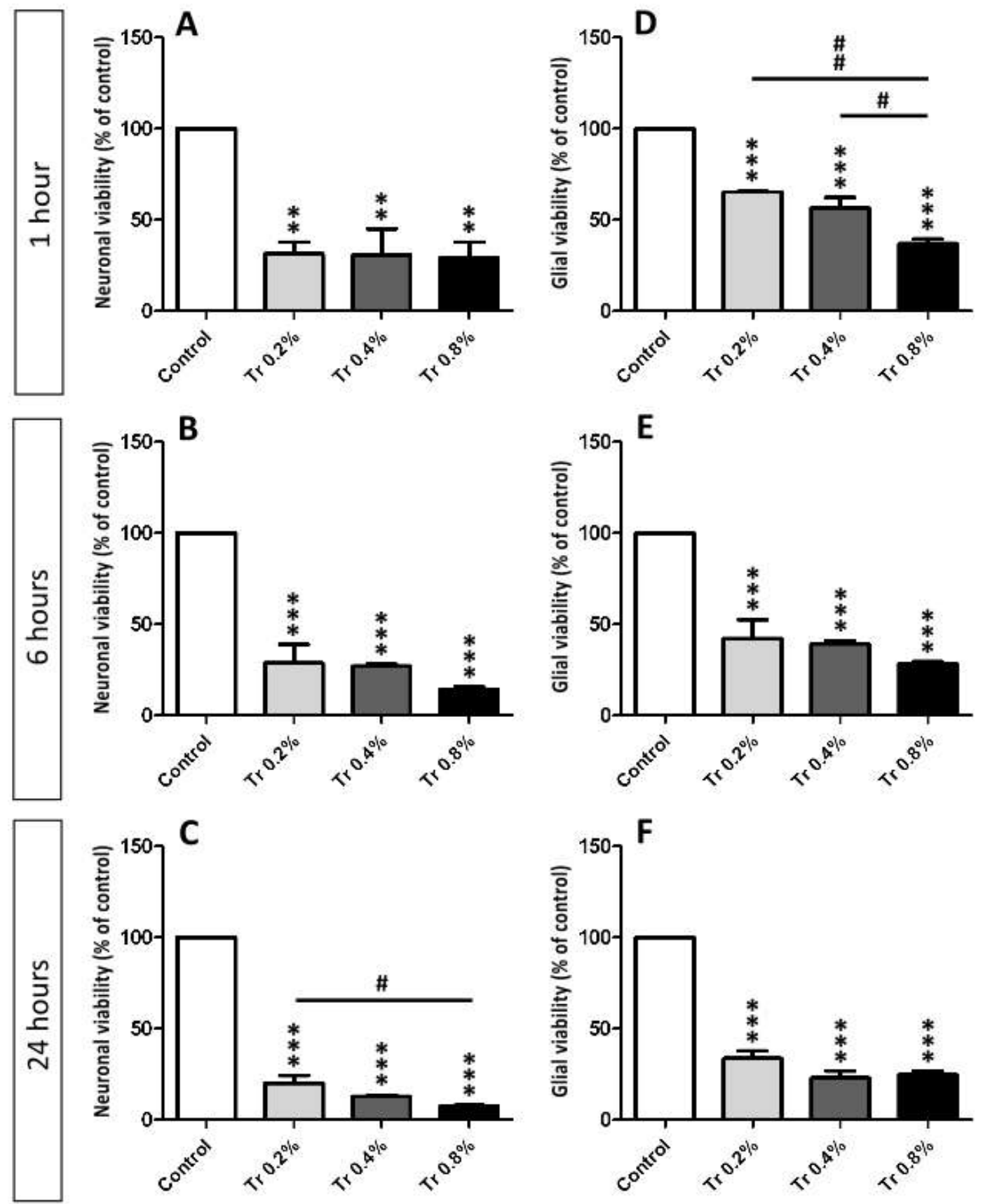

Fig -1: Percentages of neuronal (A, B and C) and glial (D, E and F) viability after $1 \mathrm{~h}, 6 \mathrm{~h}$ and $24 \mathrm{~h}$ of incubation with $0.2 \%, 0.4 \%$ and $0.8 \%$ of paint thinner. Data are means \pm SEM of three experiments. ${ }^{* *} \mathrm{P}<0.01$ and ${ }^{* * *} \mathrm{P}<0.001$ compared to control. ${ }^{*} \mathrm{P}<0.05$ and ${ }^{\# \neq} \mathrm{P}<0.01$ compared to treated group.

The addition of $0.2 \%, 0.4 \%$ or $0.8 \%$ of thinner to the culture medium for 24 hours induced also a significant decreased in the neuronal viability to respectively $19.94 \pm 7.56 \%, 12.81 \pm$ $1.11 \%$ and $7.38 \pm 0.96 \%$ of viable cells (Fig. 1C). Thus, one-way ANOVA analysis revealed a significant difference between the treated groups and the control group $\left(\mathrm{F}_{(3,8)}=\right.$ 385.05, $\mathrm{P}<0.001)$, and between the three treated groups $\left(\mathrm{F}_{(2,6)}=6.02, \mathrm{P}=0.03\right)$ after $24 \mathrm{~h}$ thinner action. Post hoc Bonferroni test analysis between treated groups showed that only the percentage of viable neurons treated with $0.2 \%$ and $0.8 \%$ of thinner were significantly different $(\mathrm{t}=3.99, \mathrm{P}<$ $0.05)$.
The statistical analysis with two-way ANOVA of all groups after three periods of incubation indicated that the dose used had a significant negative effect $\left(\mathrm{F}_{(3,24)}=111.7, \mathrm{P}<0.001\right)$ on the viability of neurons (Fig. 2A). However, nosignificant effect was observed for the incubation period, and the interaction of these two factors (respectively: $F_{(3,24)}$ $=1.64, \mathrm{P}=0.21$ and $\left.\mathrm{F}_{(6,24)}=0.37, \mathrm{P}=0.88\right)$. 


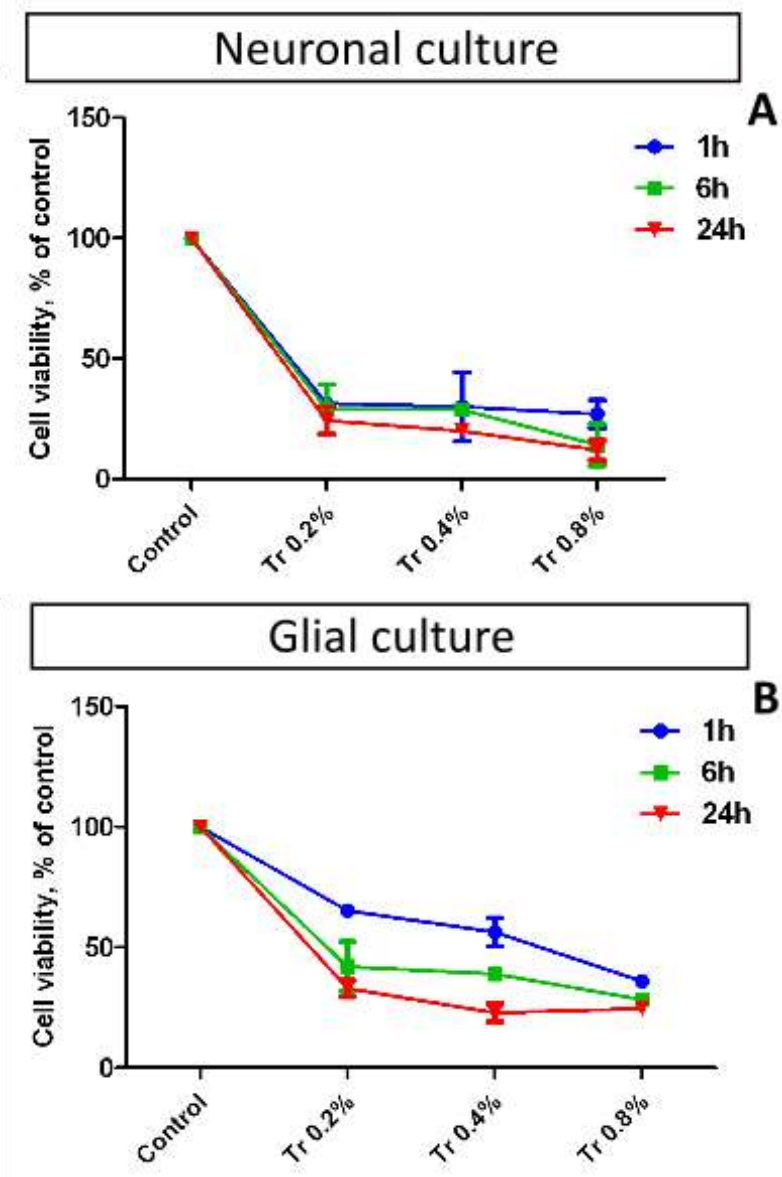

Fig -2: Neuronal (A) and glial (B) viability determined by MTT assay in cells treated for $1 \mathrm{~h}, 6 \mathrm{~h}$ and $24 \mathrm{~h}$ with $0.2 \%$, $0.4 \%$ and $0.8 \%$ of paint thinner. Data are means \pm SEM of three experiments.

\subsection{Paint Thinner Treatment Reduces Viability of}

\section{Cultured Astrocytes}

The incubation for one hour of cultured astrocytes with the paint thinner induced a reduction of percentage of viable cells (Fig. 1D). Indeed, we observed that in the treated groups, $65.35 \pm 0.64 \%, 56.39 \pm 10.22 \%$ and $36.99 \pm 4.32 \%$ of astrocytes were viable after incubation respectively with $0.2 \%, 0.4 \%$ and $0.8 \%$ of thinner. One-way ANOVA analysis showed that there was a significant difference between the treated groups and the control group $\left(\mathrm{F}_{(3,8)}=67.51, \mathrm{P}<\right.$ $0.001)$, as well as between the treated groups $\left(F_{(2,6)}=15.32\right.$, $\mathrm{P}<0.05)$. Post hoc Bonferroni test analysis between treated groups demonstrated that the effect of thinner treatment on glial viability was doses dependent. In fact, the astrocytes viability with $0.2 \%$ and $0.8 \%$ of thinner treatment was significantly different $(\mathrm{t}=6.25, \mathrm{P}<0.01)$. A significant difference was also observed treatment with $0.4 \%$ and $0.8 \%$ of thinner $(\mathrm{t}=4.28, \mathrm{P}<0.05)$.

The percentage of viability of astrocytes treated for 6 hours decreased to $42.10 \pm 17.86 \%, 39.24 \pm 2.96 \%$ and to $28.42 \pm$ $1.78 \%$, respectively in $0.2 \%, 0.4 \%$ and $0.8 \%$ treated group (Fig. 1E). These percentage values were significantly different to the control group $\left(\mathrm{F}_{(3,8)}=37.71, \mathrm{P}<0.001\right)$.
However, the difference between treated groups was not significant $\left(\mathrm{F}_{(2,6)}=1.41, \mathrm{P}=0.31\right)$.

After 24 hours of incubation, we noted that $0.2 \%, 0.4 \%$ and $0.8 \%$ of thinner induced a decrease in the glial viability respectively to $33.64 \pm 6.98 \%, 22.94 \pm 6.48 \%$ and $24.65 \pm$ $3.74 \%$ (Fig. 1F). The statistical analysis showed that the difference between control and treated cultures was highly significant $\left(\mathrm{F}_{(3,8)}=154.8, \mathrm{P}<0.001\right)$. However, no significant difference was revealed between treated groups $\left(\mathrm{F}_{(2,6)}=2.83, \mathrm{P}=0.13\right)$. Thus conversely to the neuronal survival, a doses dependent effect was only obtained at shorter incubation times over glial cultures.

Moreover, the statistical analysis with two-way ANOVA of the glial viability for all groups indicated that the effects of incubation time and dose of thinner were highly significant (respectively, $\mathrm{F}_{(2,24)}=25.37, \mathrm{P}<0.01$ and $\mathrm{F}_{(3,24)}=198.45, \mathrm{P}$ $<0.001)$, as well as the interaction of these two factors $\left(\mathrm{F}_{(6,24)}=4.72, \mathrm{P}<0.001\right)$ (Fig. 2B).

\section{DISCUSSION}

In the present study, we tested the hypothesis that neuronal and glial cell viability could be affected by paint thinner exposure. The rationale behind using thinner as solvent mixture is based on the fact that inhalation of the volatile components of thinner has become a public health problem for working painters and also as a drug abused by adolescents of low income social class. Conversely, toxicity of solvent exposure as chemical mixtures has not been studied before. Herein, we report for the first time the toxicity action of thinner on metabolic activities of neurons and astrocytes in vitro; and also we highlight the different effect on these two cell lines. Our results reveal that thinner causes cell death in cultured neurons and astrocytes after short time of incubation from a minimum paint thinner concentration.

The cytotoxicity of thinner compounds was estimated using the MTT assay. This technique evaluates cells' metabolic activities by assessing succinate dehydrogenase activity which is mostly located in the mitochondria. This test is based on the principal that only viable cells (containing functional mitochondria) could convert significant amounts of water-soluble yellow MTT dye to an insoluble, violet MTT formazan metabolite, which can be measured colorimetrically. For the assessment of acute effects of thinner treatment on neuronal cells and the evaluation of the dose- and time-response dependencies, we added different concentration of thinner $(0.0 \%, 0.2 \%, 0.4 \%$ and $0.8 \%)$ to the culture medium for different time of incubation $(1 \mathrm{~h}, 6 \mathrm{~h}$ and 24h). In order to improve the solubility of thinner compounds and therefore facilitate their absorption by the cells, the tested mixture was dissolved directly in culture medium with fetal bovine serum (10\%) [30]. In fact, to dissolve thinner, we have avoided the use in our experiments DMSO or alcohol in order to prevent the cytotoxic action of these compounds [31,32,33]. It should be pointed out that during the current protocol we used a free 
mineral oil medium, since it has been proven that this oil could dramatically affect neurons and astrocytes viability because of their intense metabolism [30]. Interestingly, cytotoxic potential of the tested solvent cannot be disrupted following the addition of fetal bovine serum to cell culture medium. However, this addition can enhance the dissolution of lipophil components of cell medium and could also be a source of growth factors and hormones, acting as a shield for isolated cells [30]. Several studies have shown that adding serum increases the survival rate of neuronal cells in long-term experiments and accelerates reconstruction of membrane receptors, neuronal attachment and neurite outgrowth which affects favorably the process of attaching neuronal cells to the bottom of microplate wells [34,35].

Our results demonstrate that this mixture of organic solvents components is cytotoxic and induces cell death at a high rate in cultured neurons and astrocytes. In addition, the toxic effect is more relevant on neurons (reduction of cell viability by approximately $70 \%$ ) than on glial cells (reduction of cell viability by about $40 \%$ ), and the viability of glial cells is the only dependent on the exposure time. This finding of reduced cell viability from increased exposure to solvent is supported by other organic solvents studies such as toluene, xylene or hexane [36,37,38]. In a similar study, Zapór et al [30] indicated that ethylbenzene, tetrachloroethylene and nhexane induced cytotoxic action on cultured hepatocytes by inhibiting metabolic activity, using the MTT assay as a method. Al-Ghamdi et al $[36,39,40]$ demonstrated also that exposed renal proximal tubular cell to toluene and xylene reduced cell viability and increased caspase- 3 and caspase- 9 activation. These authors indicated that the toxicity of toluene and xylene acute exposure involves cytochrome $\mathrm{P} 4502 \mathrm{E} 1$ activation, which participates in oxidative stress as a mediator of necrotic cell death [39]. Finally, Wichmann et al [41] observed by using the same MTT test that continuous exposure to volatile solvents resulted in decreased cell viability together with inhibition of secretion of interferongamma, interleukin-4 and intereleukin-13. This effect was parallel with increased production of tumor-necrosis-factoralpha. Thus, through these observations, we can suggest that the paint thinner compounds induce membrane damage and cause apoptotic or necrotic responses from the minimum paint thinner concentration.

Toluene, one of principal solvent components of paint thinner used, is the well-known neurotoxic agent. Although the neuropsychological effect of the acute and chronic exposure to toluene have been well documented $[42,43,44,45]$. From neurological studies, there is a substantial body of evidence on the effect of solvents on anatomical structures highly myelinated. Autopsies from long term toluene abusers reveal degeneration and gliosis of long tracks and demyelization of white matter especially in the periventricular regions, suggesting that the toluene induces metabolic changes in myelin $[7,8,46]$. It has been also reported that decrease in myelin of the corpus callosum in cases of toluene abusers could be secondary to neuronal loss in the cerebral cortex [47].

Thus, the neurotoxic effects of inhalants such as thinner are explained on the basis of an action over membrane.
According to this view, the solvent-induced changes of the lipid bilayer could impact membrane proteins function. The lipophilic properties of solvents permit them to penetrate easily with high concentrations to the CNS [48]. It is known that organic solvents induce stabilization and/or destabilization of membrane proteins structure driving to unstable cell membrane conformation [49]. Studies of the effects of toluene on membrane fluidity in vivo suggested a specific toluene-phospholipid interaction in synaptosomes which could induce changes in membrane composition and fluidity [50]. It also increases phospholipid methylation and stimulates $\mathrm{Na}+\mathrm{K}+$ adenosine triphosphatase (ATPase) activity in synaptosomes both "in vivo" and "in vitro" [51]. Moreover, it has been shown that the exposure to toluene "in vitro" inhibits the integral enzymes acetylcholinesterase and ATPase of rat synaptosomal membrane, suggesting that solvents disrupt lipid-protein interactions as a mechanism of inhibition [52].

Another possible hypothesis is that oxidative stress could a key mechanism explaining the inhalants-induced toxicity. In rodents, several studies associated the cognitive deficits reported in thinner exposed rats with high levels of reactive oxygen species (ROS) following thinner exposure [53]. In another interesting report, the same authors have demonstrated that this increased ROS levels is mediated by an increase of lipid peroxidation in different brain regions [54]. In vitro, the study of Mattia et al [55] has clearly shown that toluene exposure, leads to an exaggerated increase of ROS rate in brain tissues. Furthermore, the increased formation of ROS has been also demonstrated in cultured rat cerebellar granule cells exposed to tbutylcyclohexane, n-decane, and n-butylbenzene [56]. Finally, in Human, the study of Halifeoglu et al [57] showed an elevation of malondialdehyde levels in serum of daily exposed workers to paint thinner. They suggested that malondialdehyde mediated homeostasis imbalance between oxidant molecules and antioxidant organism defense may be a possible cause for the reported alterations. Thus, if thinner produces reactive oxygen species, the incapacity of the brain to metabolize them may explain its neurotoxic effect. Additional expertise is required to explore the relationship between oxidative stress and pathological mechanisms (apoptosis or necrosis) under thinner exposure.

\section{CONCLUSION}

The exposure to the complex mixture of the thinner has a direct effect on viability of neurons and astrocytes in culture. Our study clearly shows that there is a doses dependent effect of thinner on viability of neurons and glial cells. The effect is more relevant on neurons than on glial cells and the viability of glial cells is the only dependent on the exposure time. Finally, the MTT method has been proven to be useful as to assess the toxic effect of a combination of volatiles on neural cells.

\section{ACKNOWLEDGEMENTS}

We gratefully acknowledge Prof. S. Ahboucha for editing. This work was supported by the TEMPUS IV program (2010-2013) and Neuroscience Research Exchange Network (NEUREN). 


\section{REFERENCES}

[1]. H. Aksoy, S. Yilmaz, M. Celik, D. Yüzbaşioglu, F. Unal, Genotoxicity study in lymphocytes of offset printing workers, J. Appl. Toxicol. 26 (2006) 10-5. DOI: $10.1002 /$ jat. 1098

[2]. L.S. Hoyos-Giraldo, S. Carvajal, N. Cajas-Salazar, M. Ruíz, A. Sánchez-Gómez, Chromosome aberrations in workers exposed to organic solvents: Influence of polymorphisms in xenobiotic-metabolism and DNA repair genes, Mutat. Res. $666 \quad$ (2009) 8-15. doi:10.1016/j.mrfmmm.2009.03.003

[3]. D. Basu, OP. Jhirwal, J. Singh, S. Kumar, SK. Mattoo, Inhalant abuse by adolescents: a new challenge for Indian physicians, Indian J. Med. Sci. 58 (2004) 245-9.

[4]. J.T. Beckley, J.J. Woodward, Volatile solvents as drugs of abuse: focus on the cortico-mesolimbic circuitry, Neuropsychopharmacology. $38 \quad$ (2013) 2555-67. DOI:10.1038/npp.2013.206

[5]. M.E Patrick, L.M. Collins, E. Smith, L. Caldwell, A. Flisher, L.A. Wegner, Prospective longitudinal model of substance use onset among South African adolescents, Subst. Use. Misuse. 44 (2009) 647-62.

[6]. M. Martínez-Alfaro, Y. Alcaraz-Contreras, A. CárabezTrejo, G.E. Leo-Amador, Oxidative stress effects of thinner inhalation, Indian J. Occup. Environ. Med. 15 (2011) 87-92. DOI:10.4103/0019-5278.93195.

[7]. C.M. Filley, W. Halliday, B.K. KleinschmidtDeMasters, The effects of toluene on the central nervous system, J. Neuropathol. Exp. Neurol. 63 (2004) 1-12.

[8]. N.L. Rosenberg, B.K. Kleinschmidt-DeMasters, K.A. Davis, J.N. Dreisbach, J.T. Hormes, C.M. Filley, Toluene abuse causes diffuse central nervous system white matter changes, Ann. Neurol. 23 (1988) 611-4. DOI:10.1002/ana.410230614

[9]. D.I. Lubman, M. Yücel, A.J. Lawrence, Inhalant abuse among adolescents: neurobiological considerations, Br. J. Pharmacol. 154 (2008) 316-26. DOI:10.1038/bjp.2008.76

[10]. K. Fifel, M. Bennis, S. Ba-M'hamed, Effects of acute and chronic inhalation of paint thinner in mice: behavioral and immunohistochemical study, Metab. Brain Dis. 29 (2014) 471-82. DOI:10.1007/s11011-013-9449-4

[11]. J. Reza, G. Salazar, A. Trejo, Evaluation of composition and evaporation behavior of commercial thinner samples expended in mexico city, Rev. Int. Contam. Ambient. 13 (1997) 87-95.

[12]. V.A. Benignus, Health effects of toluene: a review, Neurotoxicology. 2 (1981) 567-88.

[13]. G. Von Euler, S.O. Ogren, X.M. Li, K. Fuxe, J.A. Gustafsson, Persistent effects of subchronic toluene exposure on spatial learning and memory, dopaminemediated locomotor activity and dopamine D2 agonist binding in the rat, Toxicology. 77 (1993) 223-32.

[14]. E.B. Evans, R.L. Balster, CNS depressant effects of volatile organic solvents, Neurosci. Biobehav. Rev. 15 (1991) 233-41.

[15]. R.J. Flanagan, M. Ruprah, T.J. Meredith, J.D. Ramsey, An introduction to the clinical toxicology of volatile substances, Drug Saf. 5 (1990) 359-83.

[16]. M.H. Chan, T.H. Chien, P.Y. Lee, H.H. Chen, Involvement of NO/cGMP pathway in toluene-induced locomotor hyperactivity in female rats,

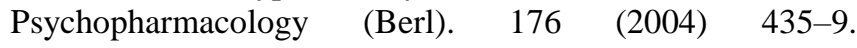
DOI:10.1007/s00213-004-1900-0

[17]. P. Kjellstrand, B. Holmquist, I. Jonsson, S. Romare, L. Månsson, Effects of organic solvents on motor activity in mice, Toxicology. 35 (1985) 35-46.

[18]. H. Kondo, J. Huang, G. Ichihara, M. Kamijima, I. Saito, E. Shibata, Y. Ono, N. Hisanaga, Y. Takeuchi, D. Nakahara, Toluene induces behavioral activation without affecting striatal dopamine metabolism in the rat: behavioral and microdialysis studies, Pharmacol. Biochem. Behav. 51(1995) 97-101.

[19]. A.C. Riegel, E.D. French, Acute toluene induces biphasic changes in rat spontaneous locomotor activity which are blocked by remoxipride, Pharmacol. Biochem. Behav. 62 (1999) 399-402.

[20]. R.W. Wood, V.A. Colotla, Biphasic changes in mouse motor activity during exposure to toluene, Fundam. Appl. Toxicol. 14 (1990) 6-14.

[21]. M.H. Chan, C.C. Lee, H.H. Chen, Effects of toluene on seizures induced by convulsants acting at distinct ligandgated ion channels, Toxicol. Lett. 160 (2006) 179-84. DOI:10.1016/j.toxlet.2005.07.002

[22]. S.L. Cruz, M.Y. Gauthereau, C. Camacho-Muñoz, C. López-Rubalcava, R.L. Balster, Effects of inhaled toluene and 1,1,1-trichloroethane on seizures and death produced by $\mathrm{N}$-methyl-D-aspartic acid in mice, Behav. Brain Res. 140 (2003) 195-202.

[23]. R.W. Wood, J.B. Coleman, R. Schuler, C. Cox, Anticonvulsant and antipunishment effects of toluene, J. Pharmacol. Exp. Ther. 230 (1984) 407-12.

[24]. S.E. Bowen, J.L. Wiley, R.L. Balster, The effects of abused inhalants on mouse behavior in an elevated plusmaze, Eur. J. Pharmacol. 312 (1996) 131-6.

[25]. C. López-Rubalcava, R. Hen, S.L. Cruz, Anxiolyticlike actions of toluene in the burying behavior and plusmaze tests: differences in sensitivity between 5-HT(1B) knockout and wild-type mice, Behav. Brain Res. 115 (2000) 85-94.

[26]. N. Páez-Martínez, S.L. Cruz, C. López-Rubalcava, Comparative study of the effects of toluene, benzene, 1,1,1trichloroethane, diethyl ether, and flurothyl on anxiety and nociception in mice, Toxicol. Appl. Pharmacol. 193 (2003) 9-16.

[27]. S.L. Valles, P. Dolz-Gaiton, J. Gambini, C. Borras, A. Lloret, F.V. Pallardo, J. Viña, Estradiol or genistein prevent Alzheimer's disease-associated inflammation correlating with an increase PPAR gamma expression in cultured astrocytes, Brain. Res. $1312 \quad$ (2010) 138-44. DOI:10.1016/j.brainres.2009.11.044

[28]. J.M. Palanca, D. Aguirre-Rueda, M.V. Granell, M. Aldasoro, A. Garcia, A. Iradi, E. Obrador, M.D. Mauricio, J. Vila, A. Gil-Bisquert, S.L. Valles, Sugammadex, a neuromuscular blockade reversal agent, causes neuronal apoptosis in primary cultures, Int. J. Med. Sci. 10 (2013) 1278-85. DOI:10.7150/ijms.6254

[29]. T. Mosmann, Rapid colorimetric assay for cellular growth and survival: application to proliferation and cytotoxicity assays, J. Immunol. Methods. 65 (1983) 55-63. [30]. L. Zapór, J. Skowroń, M. Gołofit-Szymczak, The cytotoxicity of some organic solvents on isolated 
hepatocytes in monolayer culture, Int. J. Occup. Saf. Ergon. 8 (2002) 121-9.

[31]. W. Qi, D. Ding, R.J. Salvi, Cytotoxic effects of dimethyl sulphoxide (DMSO) on cochlear organotypic cultures, Hear. Res. 236 (2008) 52-60.

[32]. J. Hebling, L. Bianchi, F.G. Basso, D.L. Scheffel, D.G. Soares, M.R. Carrilho, D.H. Pashley, L. Tjäderhane, C.A. de Souza Costa, Cytotoxicity of dimethyl sulfoxide (DMSO) in direct contact with odontoblast-like cells, Dent. Mater. (2015) DOI: 10.1016/j.dental.2015.01.007.

[33]. E. Korkotian, A. Botalova, T. Odegova, M. Segal, Chronic exposure to alcohol alters network activity and morphology of cultured hippocampal neurons. Neurotoxicology. (2015) DOI: 10.1016/j.neuro.2015.01.005. [34]. A. Hashimoto, T. Onodera, H. Ikeda, H. Kitani, Isolation and characterisation of fetal bovine brain cells in primary culture, Res. Vet. Sci. 69 (2000) 39-46. DOI:10.1053/rvsc.2000.0382

[35]. X.F. Wang, M.S. Cynader, Effects of astrocytes on neuronal attachment and survival shown in a serum-free coculture system, Brain Res. Protoc. 4 (1999) 209-16.

[36]. S.S. Al-Ghamdi, M.J. Raftery, M.M. Yaqoob, Organic solvent-induced proximal tubular cell toxicity via caspase-3 activation, J. Toxicol. Clin. Toxicol. 41 (2003) 941-5.

[37]. S. Bakand, C. Winder, C. Khalil, A. Hayes, A novel in vitro exposure technique for toxicity testing of selected volatile organic compounds, J. Environ. Monit. 8 (2006) 100-5. DOI:10.1039/b509812b

[38]. C. McDermott, A. Allshire, F.N.A.M van Pelt, J.J.A. Heffron. Validation of a method for acute and subchronic exposure of cells in vitro to volatile organic solvents, Toxicol. In Vitro. $21 \quad$ (2007) 116-24. DOI:10.1016/j.tiv.2006.08.002

[39]. S.S. Al-Ghamdi, M.J. Raftery, M.M. Yaqoob, Acute solvent exposure induced activation of cytochrome P4502E1 causes proximal tubular cell necrosis by oxidative stress, Toxicol. In Vitro. 17 (2003) 335-41.

[40]. S.S. Al-Ghamdi, M.J. Raftery, M.M. Yaqoob, Organic solvent-induced proximal tubular cell apoptosis via caspase9 activation, Environ. Toxicol. Pharmacol. 16 (2004) 14752. DOI:10.1016/j.etap.2003.12.002

[41]. G. Wichmann, J. Mühlenberg, G. Fischäder, C. Kulla, M. Rehwagen, O. Herbarth, I. Lehmann, An experimental model for the determination of immunomodulating effects by volatile compounds, Toxicol. In Vitro. 19 (2005) 685-93. DOI:10.1016/j.tiv.2005.03.012

[42]. P. Berenguer, C. Soulage, D. Perrin, J.M. Pequignot, J.H. Abraini, Behavioral and neurochemical effects induced by subchronic exposure to $40 \mathrm{ppm}$ toluene in rats, Pharmacol. Biochem. Behav. 74 (2003) 997-1003.

[43]. M. Von Euler, T.M. Pham, M. Hillefors, B. Bjelke, B. Henriksson, G. von Euler, Inhalation of low concentrations of toluene induces persistent effects on a learning retention task, beam-walk performance, and cerebrocortical size in the rat, Exp. Neurol. 163 (2000) 1-8.

[44]. D. Wiaderna, T. Tomas, Effects of repeated exposure to toluene or amphetamine on locomotor activity in rats, Int. J. Occup. Med. Environ. Health. 13 (2000) 317-24.

[45]. M. Yücel, M. Takagi, M. Walterfang, D.I. Lubman, Toluene misuse and long-term harms: a systematic review of the neuropsychological and neuroimaging literature,
Neurosci. Biobehav. Rev. 32 (2008) 910-26. DOI:10.1016/j.neubiorev.2008.01.006

[46]. N.L. Rosenberg, M.C. Spitz, C.M. Filley, K.A. Davis, H.H. Schaumburg, Central nervous system effects of chronic toluene abuse-clinical, brain stem evoked response and magnetic resonance imaging studies, Neurotoxicol. Teratol. 10 (1988) 489-95.

[47]. A. Escobar, C. Aruffo, Chronic thinner intoxication: clinico-pathologic report of a human case, J. Neurol. Neurosurg. Psychiatry. 43 (1980) 986-94.

[48]. Y. Velibey, S. Altay, S. Terzi, K. Yesilcimen, Y. Golcuk, E. Gunay, Acute myocardial infarction associated with thinner abuse: case report and literature review, Clin. Toxicol. 51 (2013) 725-6.

[49]. I.T. Ivanov, Rapid method for comparing the cytotoxicity of organic solvents and their ability to destabilize proteins of the erythrocyte membrane, Pharmazie. 56 (2001) 808-9.

[50]. C.P. LeBel, R.A. Schatz, Effect of toluene on rat synaptosomal phospholipid methylation and membrane fluidity, Biochem. Pharmacol. 38 (1989) 4005-11.

[51]. C.P. Lebel, R.A. Schatz, Altered synaptosomal phospholipid metabolism after toluene: possible relationship with membrane fluidity, $\mathrm{Na}+, \mathrm{K}(+)$-adenosine triphosphatase and phospholipid methylation, J. Pharmacol. Exp. Ther. 253 (1990) 1189-97.

[52]. M. Engelke, H. Diehl, H. Tähti, Effects of toluene and n-hexane on rat synaptosomal membrane fluidity and integral enzyme activities, Pharmacol. Toxicol. 71 (1992) 343-7.

[53]. G. Baydas, F. Ozveren, M. Tuzcu, A. Yasar, Effects of thinner exposure on the expression pattern of neural cell adhesion molecules, level of lipid peroxidation in the brain and cognitive function in rats, Eur. J. Pharmacol. 512 (2005) 181-7. DOI:10.1016/j.ejphar.2005.02.038

[54]. G. Baydas, R.J. Reiter, V.S. Nedzvetskii, A. Yaşar, M. Tuzcu, F. Ozveren, H. Canatan, Melatonin protects the central nervous system of rats against toluene-containing thinner intoxication by reducing reactive gliosis, Toxicol. Lett. 137 (2003) 169-74.

[55]. C.J. Mattia , C.P. LeBel , S.C. Bondy , Effects of toluene and its metabolites on cerebral reactive oxygen species generation, Biochem. Pharmacol. 42 (1991) 879-82. [56]. A. Dreiem, O. Myhre, F. Fonnum, Relationship between lipophilicity of C6-10 hydrocarbon solvents and their ROS-inducing potency in rat cerebellar granule cells, Neurotoxicology. 23 (2002) 701-9.

[57]. I. Halifeoglu, H. Canatan, B. Ustundag, N. Ilhan, F. Inanc, Effect of thinner inhalation on lipid peroxidation and some antioxidant enzymes of people working with paint thinner, Cell Biochem. Funct. 18 (2000) 263-7. 